\title{
Effect of Fineness Modulus of Reactive Aggregate on Alkali Silica Reaction
}

\author{
Ssang-Sun Jun ${ }^{1)}$ and Chi-Sub $\mathrm{Jin}^{2)}$
}

(Received July 14, 2010, Revised October 25, 2010, Accepted October 29, 2010)

\begin{abstract}
In this study, the effects of the fineness modulus of reactive aggregate on ASR expansion and ASR products have been investigated. The reactive aggregate used was metamorphic aggregate originated from Korea. ASR tests were conducted according to accelerated mortar bar test. The morphology and chemical composition of products formed in mortar bars, 5 years after the mortar bar test had been performed, were studied by scanning electron microscopy equipped with energy dispersive spectroscopy. Test results indicated that ASR expansion of mortar bars decrease in linear proportion to the fineness modulus of reactive aggregate. SEM images indicated that mortar bars showed reactive products formed in cement paste, within air voids and within cracks through particles except for the mortar bar with the fineness modulus of 3.25. The EDS analysis of the reactive products showed presence of silica, calcium and sodium, typical of ASR product composition.
\end{abstract}

Keywords: alkali-silica reaction, reactive aggregate, reactive product, fineness modulus, mortar bar method.

\section{Introduction}

Since the 1940's, many studies have been made on the alkalisilica reaction (ASR). It is well known that alkali-silica reactivity is usually derived from the alkalis $\left(\mathrm{Na}^{+}, \mathrm{K}^{+}\right)$in cement and reactive minerals present within aggregates. The reaction forms alkalisilica gel, which absorbs water and causes expansion and cracking of aggregates and concrete. Typical methods established to avoid the occurrence of the reaction include the use of non-reactive aggregates, limiting the level of alkalis in concrete, and the addition of supplementary cementitious materials to the concrete. ${ }^{4,5}$ The best way to solve ASR problem is to use an aggregate identified as non-reactive by test methods for the assessment of ASR. However, some researchers point out problems with the method of the test. $^{5-7}$ The more serious problem is that sources of natural aggregates are being depleted around the world ${ }^{8}$ including Korea. ${ }^{9}$ Papers on ASR have recommended to use low-alkali cement with less than $0.6 \%$ alkali content to prevent ASR-related problem. In order to use low-alkali cement, the alkali content of cement has to be controlled but it has been reported that modern dry-process of cement has led to increase in its alkali content. ${ }^{8}$ According to the investigation reported by Jun, ${ }^{10}$ cements manufactured in nine domestic cement companies are classified as "high-alkali cement," with the equivalent $\mathrm{Na}_{2} \mathrm{O}\left(\mathrm{Na}_{2} \mathrm{O}_{\text {eq }}\right)$ of $0.73 \sim 1.02 \%$. Previous investigations on ASR in Korea indicated that only several

\footnotetext{
${ }^{1)}$ KCI Member, Dept. of Civil Engineering, Korea Maritime University, Busan, 606-791, Korea. Email: ssjun97@gmail.com. ${ }^{2)}$ KCI Member, Dept. of Civil Engineering, Pusan National University, Busan, 609-735, Korea.

Copyright (c) 2010, Korea Concrete Institute. All rights reserved, including the making of copies without the written permission of the copyright proprietors.
}

crushed stones had been identified as reactive aggregates, ${ }^{9,11}$ damages to the concrete structures on ASR had not been reported yet. That may be why engineers of Korea were not aware of the ASR. However, since deterioration on ASR often occurs after 5 to 15 years or more and in recent studies the alkali-silica reactivity of crushed stones originated from Korea is being identified, ${ }^{9,10}$ more attention on ASR-related problems is required, and extensive research on ASR should also be continuously performed. It is important that not only engineers but also material scientists recognize this subject.

Some studies show that the size of aggregate particles can affect the ASR expansion. ${ }^{3,12-14}$ Multon et al. ${ }^{12}$ obtained significant ASR expansion for coarse particles $(1.25 \sim 3.15 \mathrm{~mm})$ and noted some research works showed ASR expansion for very small particles. ${ }^{15}$ Feng et al. reported that the grain size of $0.3 \sim 0.6 \mathrm{~mm}$ influenced the expansion. ${ }^{13}$ As a part of the work on ASR, this paper studied the effect of the fineness modulus of reactive aggregates on ASR expansion and a correlation between the fineness modulus of reactive aggregates and ASR expansion values. A high FM mean the aggregate is combined in coarser particles. It is thought that this is as important as the grain size effect alone. ASR tests were conducted according to accelerated mortar bar method (ASTM C 1260 ) which is the most widely used test method. ${ }^{5}$ The morphology and chemical composition of products formed in mortars, 5 years after the mortar bar had been made, were examined by scanning electron microscopy (SEM) equipped with energy dispersive spectroscopy (EDS).

\section{Experimental program}

\subsection{Materials}

Cement used in the experiment was ordinary Portland cement 
Table 1 Chemical compositions of cement (unit: \%).

\begin{tabular}{c|c|c|c|c|c|c|c}
\hline $\mathrm{SiO}_{2}$ & $\mathrm{Al}_{2} \mathrm{O}_{3}$ & $\mathrm{Fe}_{2} \mathrm{O}_{3}$ & $\mathrm{CaO}$ & $\mathrm{MgO}$ & $\mathrm{SO}_{3}$ & $\mathrm{~K}_{2} \mathrm{O}$ & $\mathrm{Na}_{2} \mathrm{O}$ \\
\hline \hline 20.5 & 6.0 & 3.1 & 61.6 & 3.2 & 2.1 & 0.95 & 0.12 \\
\hline
\end{tabular}

manufactured in Korea with an alkali content $0.75(\%)$ in terms of equivalent $\mathrm{Na}_{2} \mathrm{O}\left(\mathrm{Na}_{2} \mathrm{O}_{\mathrm{eq}}=0.658 \mathrm{~K}_{2} \mathrm{O}+\mathrm{Na}_{2} \mathrm{O}\right)$. The chemical compositions of cement are presented in Table 1.

Aggregates-crushed aggregates estimated as deleterious by the accelerated mortar bar test (ASTM C 1260) were used. ${ }^{10}$ The reactive aggregates used in this experiment are a metamorphic rock (hornfels), which is originated from Korea. Results of physical property tests of aggregates are tabulated in Table 2 .

\subsection{Experimental condition}

Aggregates used in this experiment were crushed and graded to sieves required in a sieve analysis test of fine aggregates. Sieves used were No. 4 (5.0 mm), No. 8 (2.5 mm), No. 16 (1.2 mm), No. $30(0.6 \mathrm{~mm})$, No. $50(0.3 \mathrm{~mm})$ and No. $100(0.15 \mathrm{~mm})$. The aggregate samples were divided into five particle size fractions: aggregates retained on the No. 8 sieve, aggregates retained on the No. 16 sieve, aggregates retained on the No. 30 sieve, aggregates retained on the No. 50 sieve and aggregates retained on the No. 100 sieve. Since different aggregate grading may have the same fineness modulus (FM) ${ }^{14}$ in order to obtain each different FM, the percentages by weight retained on each of the specified series of sieves were varied (Table 3). Table 3 shows mixing proportions of aggregate retained in various sizes of sieves and the grading of the samples is represented in Fig. 1. In Table 3 and Fig. 1, the grading of the Case B is that of crushed aggregate required in ASTM C 1260 and C 227 test method for the assessment of ASR expansion. The value of the FM of the Case B is 2.90. Based on the grading of the Case B, grading for the test was set, and the FM was calculated.

\subsection{Test methods}

\subsubsection{Mortar bar test}

Alkali-silica reaction tests of mortar bars were conducted following the procedures of ASTM C 1260 method. In this test method, the expansion of mortar bar is labeled as innocuous if it does not exceed $0.1 \%$ at 16 days after casting. A graded aggregate (reactive) to cement mass ratio was 2.25 and a water to cement ratio was 0.47 . Grading of all aggregates was applied in accordance with the conditions given in Table 3 . The mortar prisms were cast in $25 \times 25 \times 300 \mathrm{~mm}^{3}$ molds. The specimens were demoulded one day after casting, and then the initial length of the samples was measured. Specimens were put in a water bath at $80^{\circ} \mathrm{C}$ for 24 hours prior to making the zero reading. The mortar bars were (after the zero reading) stored in $1 \mathrm{~N} \mathrm{NaOH}$ solution at $80^{\circ} \mathrm{C}$ during the test period.

\subsubsection{Scanning electron microscopy (SEM)}

Morphologies and semi-quantitative chemical compositions of
Table 3 Mixing proportions of aggregate retained on various sizes of sieves.

\begin{tabular}{c|c|c|c|c}
\hline \multirow{2}{*}{ Case } & \multicolumn{4}{|c}{ Mass (\%) } \\
\cline { 2 - 5 } & A & B & C & D \\
\hline \hline No.8 $(2.5 \mathrm{~mm})$ & 5 & 10 & 5 & 5 \\
No.16 $(1.2 \mathrm{~mm})$ & 35 & 25 & 5 & 5 \\
No.30 $(0.6 \mathrm{~mm})$ & 45 & 25 & 55 & 45 \\
No.50 $(0.3 \mathrm{~mm})$ & 10 & 25 & 20 & 15 \\
No.100 $(0.15 \mathrm{~mm})$ & 5 & 15 & 15 & 30 \\
\hline Fineness modulus* & 3.25 & 2.90 & 2.65 & 2.40 \\
\hline
\end{tabular}

* For a fine aggregate, fineness modulus (FM) is calculated from the cumulative percentages of aggregate retained on sieves No. 4, 8, 16, 30, 50, 100 divided by 100 .

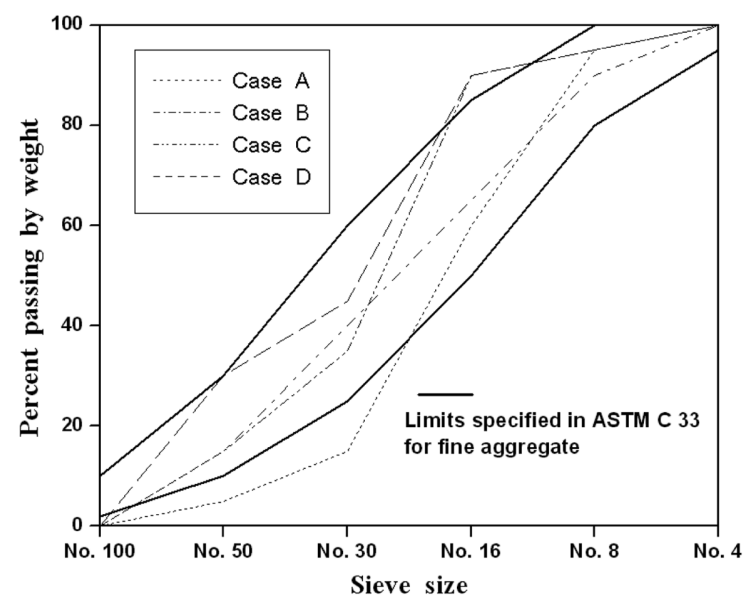

Fig. 1 Grading of samples used in this experiment.

products formed in mortar, which is 5 years old after the mortar bar test had been performed, were analyzed with scanning electron microscopy (SEM) equipped with energy dispersive spectroscopy (EDS). Representative samples with a thickness of $7 \mathrm{~mm}$ along the length of mortars were prepared. Cross sections from mortar bars were prepared for SEM secondary electron imaging (SEI). The cross sections were coated with a thin film of gold before the SEM SEI observation. The accelerating voltage used was $15 \mathrm{kV}$. Polished sections from mortars were also prepared for SEM backscattered electron imaging (BSEI) and EDS. In order to prepare polished sections, cross sections from mortars were vacuum impregnated with Epoxy EPO-TEK and were oven-dried at $60^{\circ} \mathrm{C}$ for one day. The samples were cooled and were polished with a final grit of $0.25 \mu \mathrm{m}$ diamond polishing compound. The polished sections were then coated with a thin film of carbon before the SEM BSEI observation. The morphology and chemical composition of products were determined on cross sections and polished sections of mortar bars, respectively.

\section{Experimental results}

\subsection{Mortar bar test results}

The expansion of mortar bars on ASR versus the FM of reactive

Table 2 Physical properties of aggregates.

\begin{tabular}{c|c|c|c|c}
\hline Density $\left(\mathrm{g} / \mathrm{cm}^{3}\right)$ & Absorption (\%) & Bulk density kg/m $\left(\mathrm{lb} / \mathrm{ft}^{3}\right)$ & $\begin{array}{c}\text { Amount of material finer than } \\
\text { No. } 200(0.08 \mathrm{~mm}) \text { sieve }(\%)\end{array}$ & Organic impurities \\
\hline \hline 2.64 & 2.08 & $1,557(97)$ & 5.16 & Color lighter than the standard color solution \\
\hline
\end{tabular}




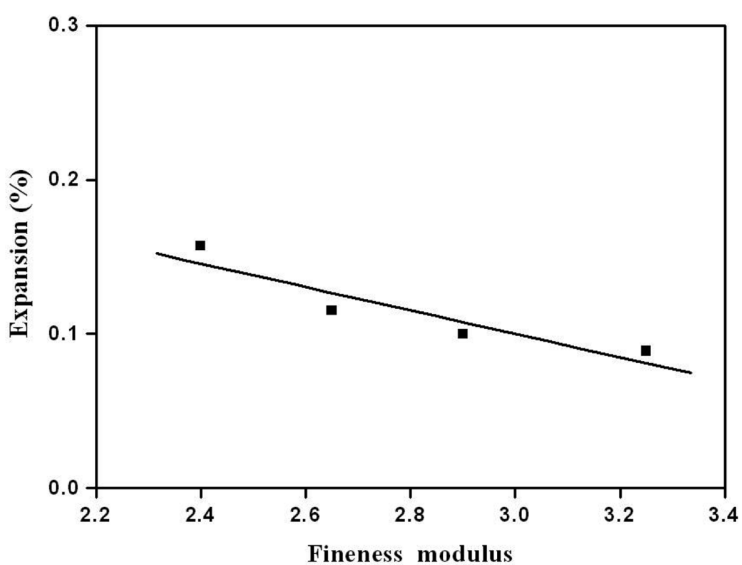

Fig. 2 Expansion on ASR versus fineness modulus of reactive aggregate.

metamorphic aggregate is represented in Fig. 2. The expansion of the mortar bars was determined as the average expansion of three specimens for each batch. Fig. 2 is shown as a function of 14 days ASR-related expansion. As shown in Fig. 2, mortar bars with the smaller FM show a bigger expansion value. It was also found that ASR expansion of mortar bars decreases in almost linear proportion to the FM. It can be seen from the linear relationship of the plot (linear regression analysis, $\mathrm{R}^{2}=0.93$ ) that when the $\mathrm{FM}$ of reactive metamorphic aggregate is more than 3.0, expansions of mortar bars meet the criterion of ASTM C 1260 test method $(0.1 \%)$. A high FM mean the aggregate is combined in coarser particles. That is, the higher the FM, the coarser the aggregate. The results of mortar bar test showed that the smaller particle size of reactive aggregate or fineness modulus caused more significant
ASR expansion. Thus, it is considered that small reactive particles influence the ASR expansion.

\subsection{SEM/EDS analysis}

Microstructural studies of mortar bars with four different types of grading were studied by SEM equipped with EDS analyzer. SEM secondary electron image (SEI) was used to observe the morphology of products formed in mortar bars. SEM backscattered electron image (BSEI) was used to measure the chemical composition of samples. Fig. 3 shows selected SEM SE images of cross sections taken from mortars with each different grading. Fig. 3(a) is an SEM micrograph of cross section taken from mortar bars with the FM of 3.25 (Case A), showing faint micro-cracks in the cement matrix. The surface of mortar bar is partially rough but the physical bond between particles and cement paste is generally intimate, and no traces of ASR can be seen. Fig. 3(b) shows the micrograph of specimens with the FM of 2.9 (Case B) presented in Table 3 and Fig. 1. As seen in Fig. 3(b), gel with smooth and cracked surfaces was observed on the interior of an air void in mortar bar, but the frequency of such occurrences was low. Figs. 3(c) and (d) are micrographs of mortar bars with FM of 2.65 (Case C) and 2.4 (Case D), respectively. In these figures, it can be observed that there are products having the lath-shaped morphology on the surface of cross sections. The morphologies of the reactive products were similar to those of typical ASR products in the literature. In mortar bars with the smallest FM (Case D) in this experiment, it was detected that there are cracks along the interface between a cement matrix and aggregates.

Fig. 4 shows BSE image and EDS analysis of polished cross section taken from mortar bars with the grading of Case A (Fig. 1 and Table 3). As shown in Fig. 4, the cement paste is generally

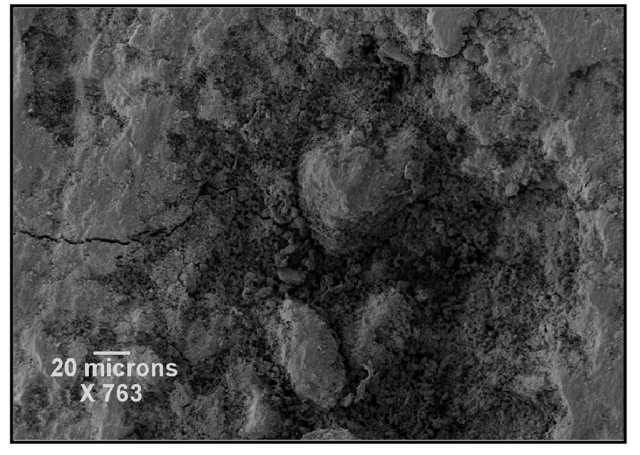

(a) Case $\mathrm{A}$

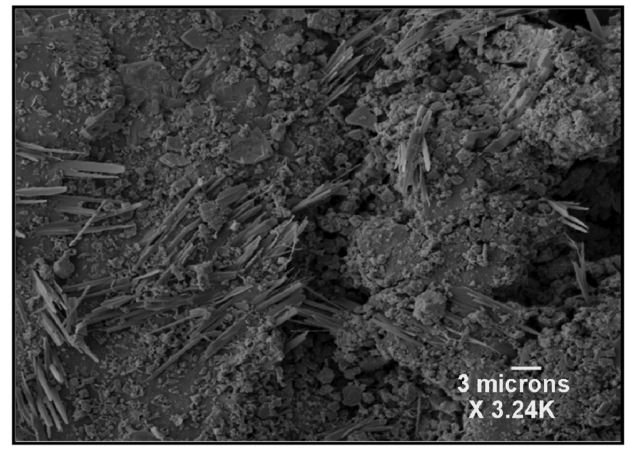

(c) Case C

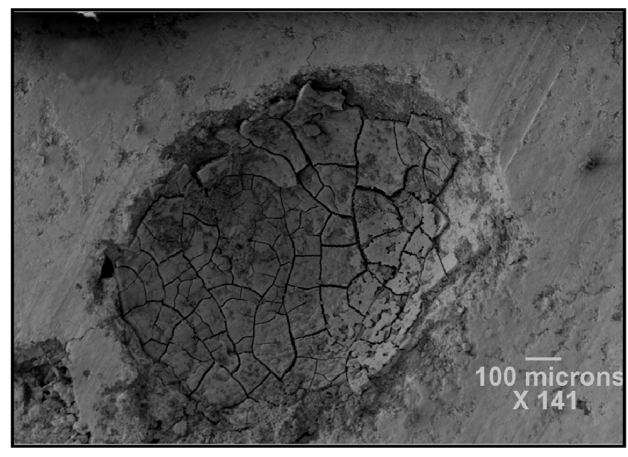

(b) Case B

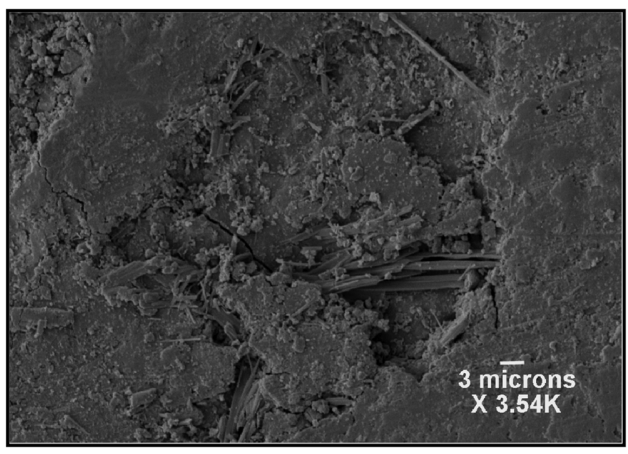

(d) Case D

Fig. 3 SEM SE images of cross sections taken from mortars with four different types of grading. Cases A, B, C and D present mortar bars with the fineness modulus of $3.25,2.90,2.65$ and 2.40 , respectively. 


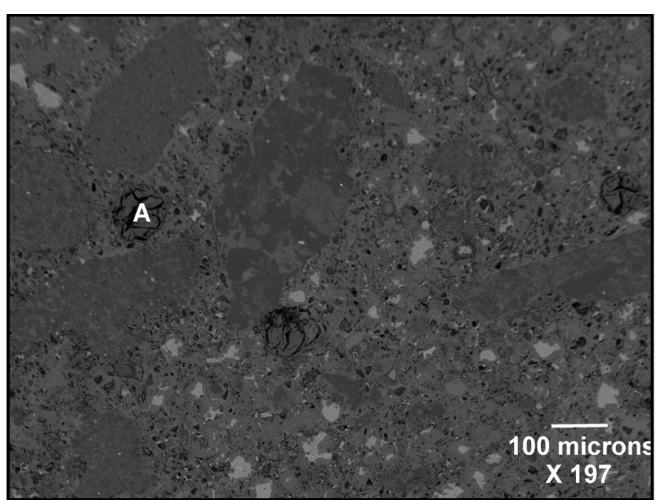

(a)

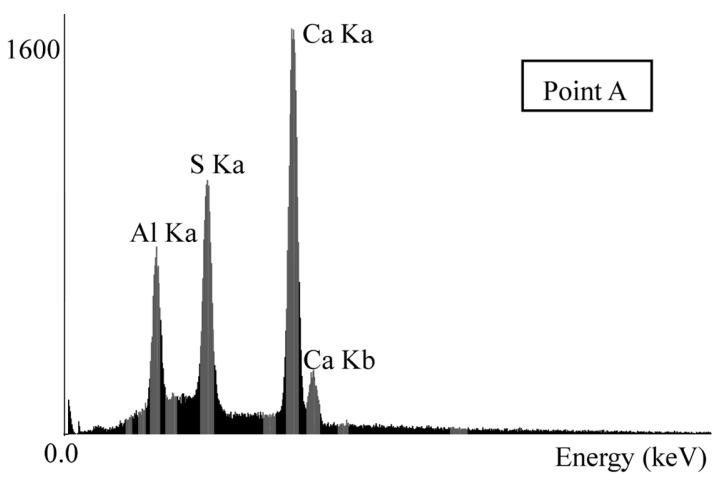

(b)

Fig. 4 BSE image and EDS analysis of polished section taken from mortar bar with 3.25 FM.

sound, and no crack or reactive product was observed. Air voids were totally filled by ettringite. The composition of the ettringite was confirmed by SEM EDS (Fig. 4(b)). Figure 5 shows micro- graphs of polished surfaces of mortar bars with the grading of Case B and EDS analyses of products formed in the mortar bars. The BSE images of cross sections show that there are products on

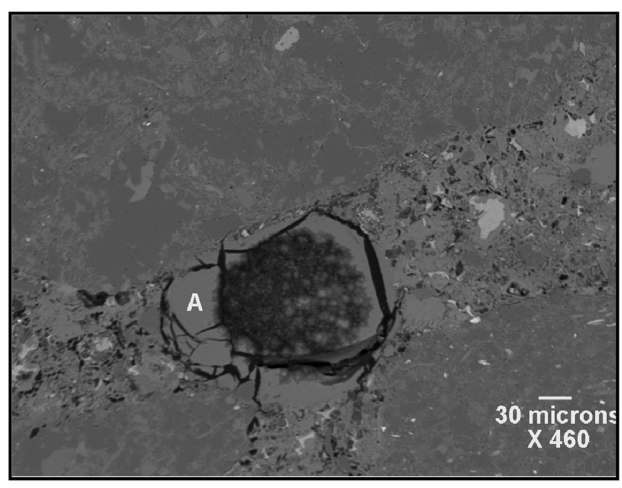

(a)

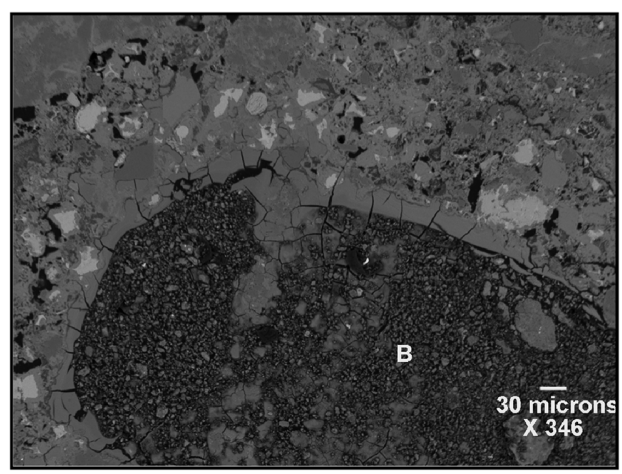

(c)

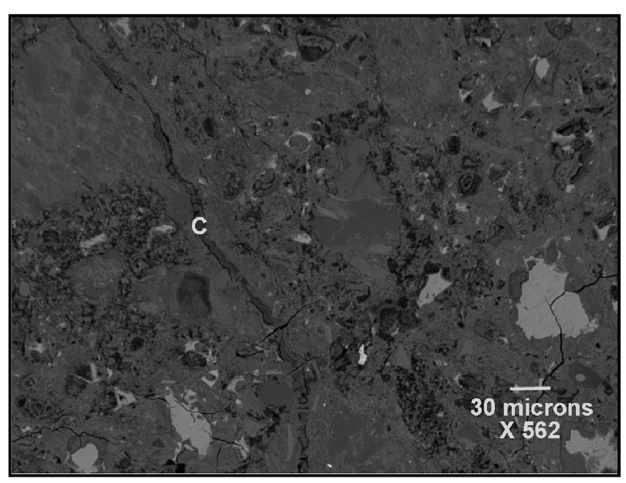

(e)

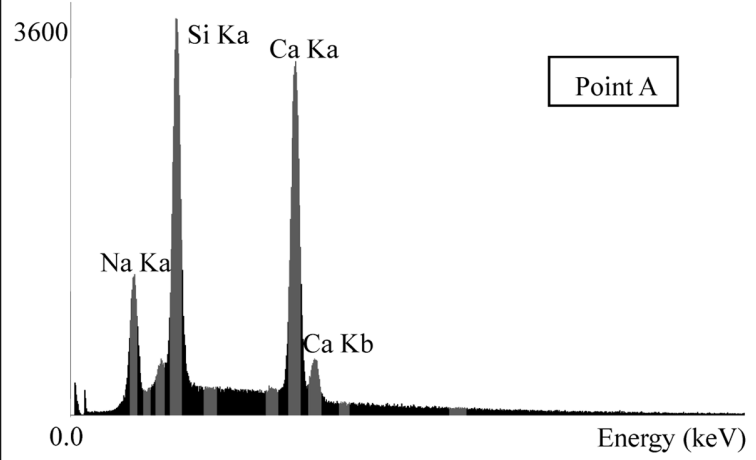

(b)
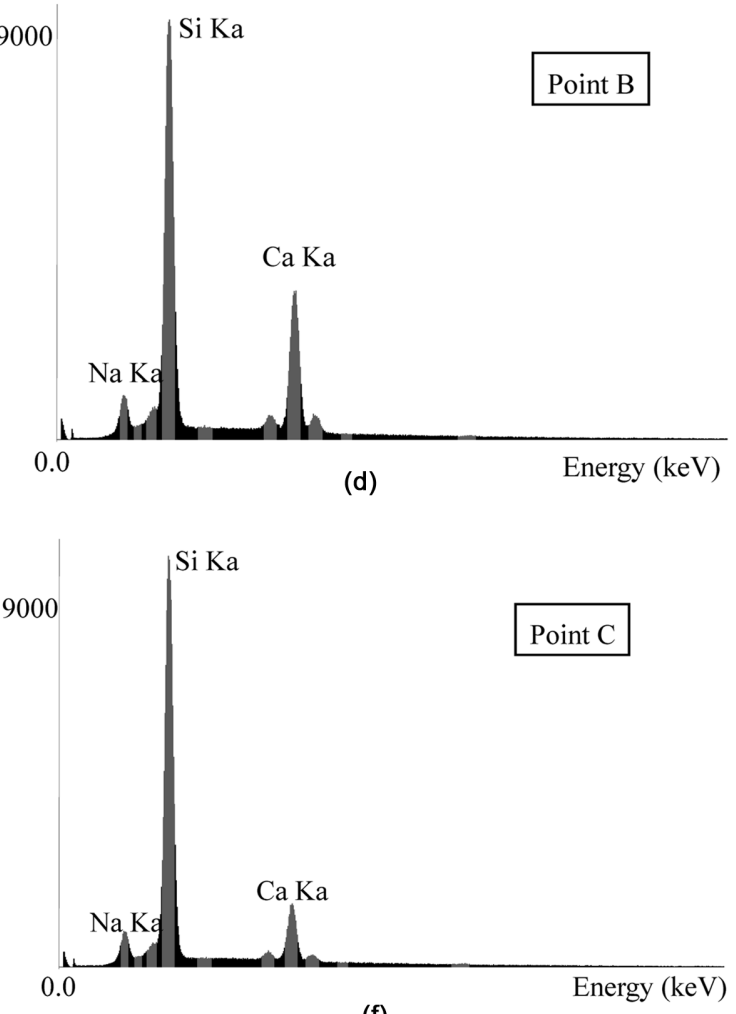

(f)

Fig. 5 BSE images and EDS analyses of polished section taken from mortar bar with 2.9 FM. 
the cement paste, within air void and within cracks through particles. The elemental compositions of the products are $\mathrm{Si}, \mathrm{Ca}$ and $\mathrm{Na}$, typical ASR product composition. ${ }^{17,18}$ It was observed that silica peak height to calcium peak height ratios of reactive products generated in each different position, marked by A, B and C, were about 1.13, 2.82 and 5.3, respectively. These results were obtained from four to six points located within a selected product. The BSE images and EDS patterns of specimens taken from mortar bars with the grading of Case $\mathrm{C}$ are shown in Fig. 6 . It can be seen that product with cracked surface is observed in the interior of air voids and cracks through particles were also observed. Also, reactive products were detected within the cracks through the particles. Products marked by A and B respectively are composed of silica, calcium and sodium. Fig. 7 shows micrographs and EDS analysis of polished cross sections of mortar bar with the grading Case D. The micrograph of product almost similar to product observed in the mortar bar with the grading of Case B (Fig. 5(C)) is observed in the mortar bar with the grading of Case D (Fig. 7(a)). However, EDS analysis shows different pattern (Figs. 5(d) and 7(c)). As seen in the Fig. 7, the elemental compositions of products (point $\mathrm{B}$ ) in the pore are $\mathrm{Si}, \mathrm{Ca}, \mathrm{Al}$ and $\mathrm{Na}$ (Fig. 7(c)). The BSE images of cross sections show that surface of mortar bar is damaged (Fig. 7(d) and (e)).

\section{Discussions}

The mortar bar test results showed that expansion values were different on the fineness modulus (FM) of reactive aggregates. It was found that there was a correlation between the FM of reactive aggregates and expansion values. The expansion values of mortar bars were larger for lower the FM of reactive aggregates. This result shows that small reactive particles influence the ASR expansion. SEM secondary electron images of cross sections taken from mortar bars revealed the morphology of reaction products on the surface, except the mortar bars with the FM of 3.25 (Case A presented in Fig. 1 and Table 3) which did not exceed $0.1 \%$ expansion. It can be observed that the mortar bar with the FM of 2.9 (Case B), which exceeded $0.1 \%$ expansion, have gel with smooth and cracked surfaces on the interior of air voids. The mortar bars with 2.65 FM (Case C) and 2.4 FM (Case D), which had more than $0.1 \%$ expansion, showed products having the lathshaped morphology on the surface. The morphologies of products detected on the surface of the mortar bars were similar to those for ASR product described by other authors. ${ }^{1,16}$ When compared with other mortar bars, the mortar bar had the greatest expansion, which is with the grading of Case D, showed that the physical bond between particle and cement matrix was not intimate and surface was damaged. In SEM backscattered electron images, ASR products were detected within mortar bars with each different grading, except that the mortar bar with the FM of 3.25 (Case A). Mortar bar with 3.25 FM showed that the cement matrix was sound and any reactive products were not detected, and air voids were filled with ettringite, even though the mortar bar was made with reactive aggregate. In BSE images, mortar bars with grading of Case B (2.9 FM) and D (2.4 FM) showed a micrograph having the same form (Figs. 5(c) and 7(a)). However, EDS patterns of products in the pore were different (Figs. 5(d) and 7(c)). The elemental composition of the products in a pore of mortar bars with the grading of Case D was Si, Ca, Al and Na (Fig. 7(a) and (c)). Silica peak height to calcium peak height ratios of products in the pores of mortar bars with grading of Case B and D were about 2.82 and 4.93 , respectively. The mortar bar had the greatest expan-

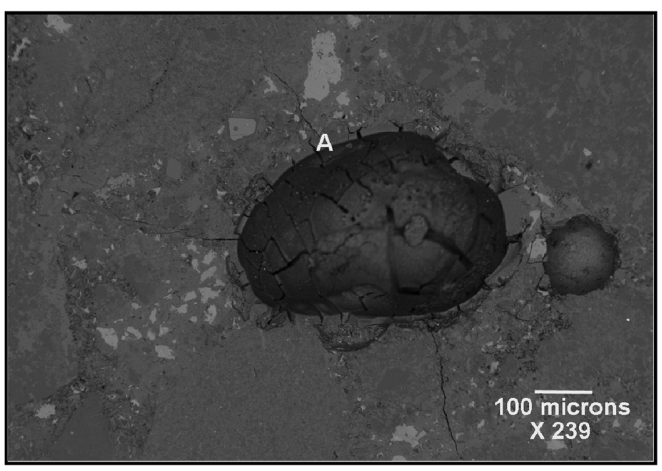

(a)

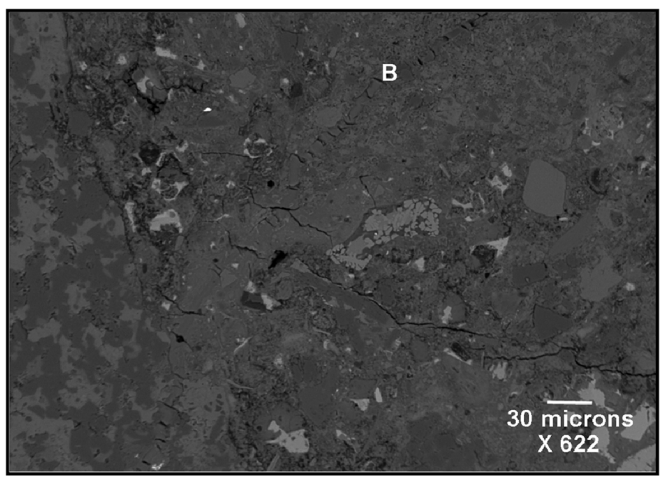

(c)

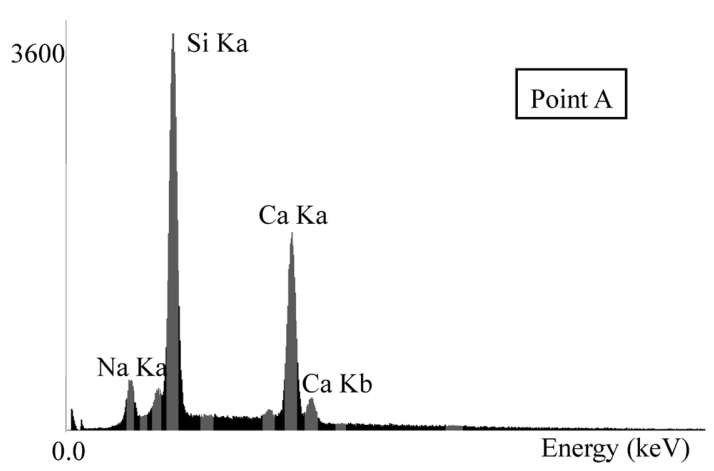

(b)

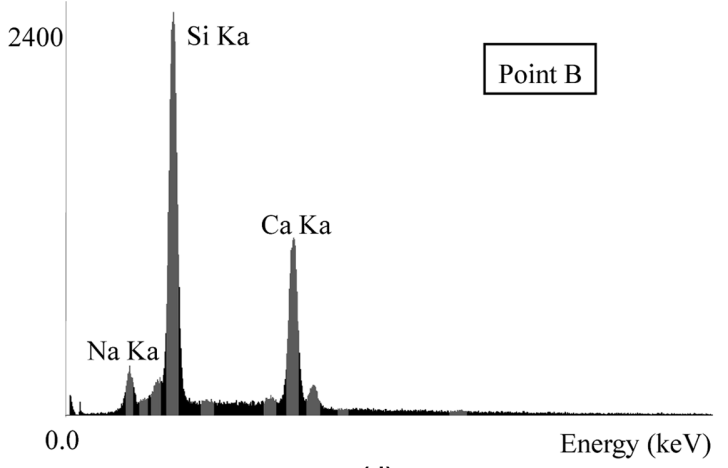

(d)

Fig. 6 BSE images and EDS analyses of polished section taken from mortar bar with 2.65 FM. 


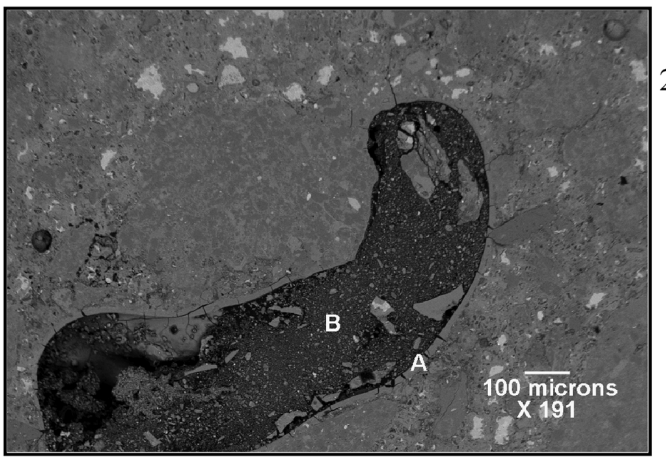

(a)

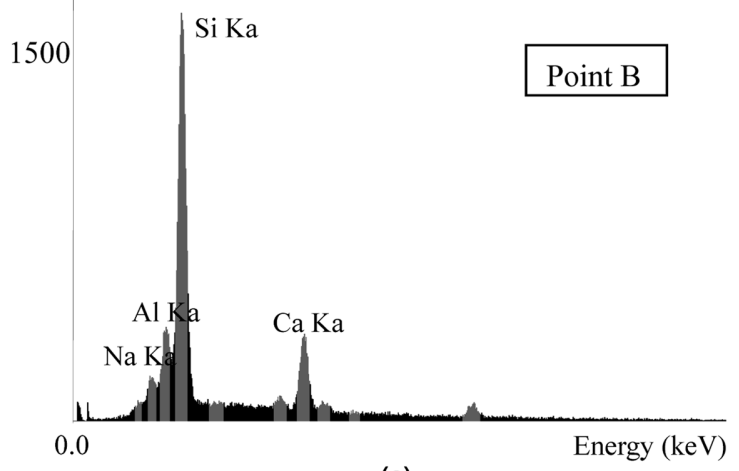

(c)

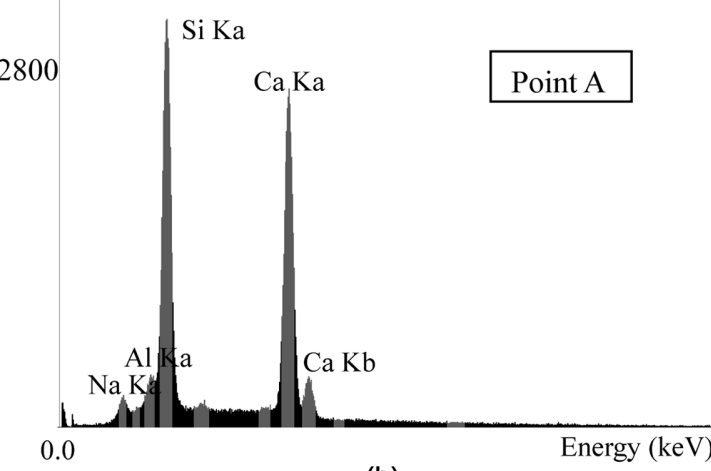

(b)

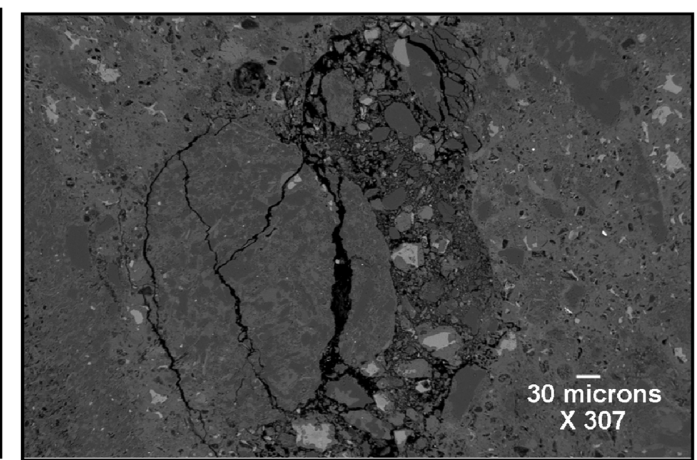

(e)

(d)

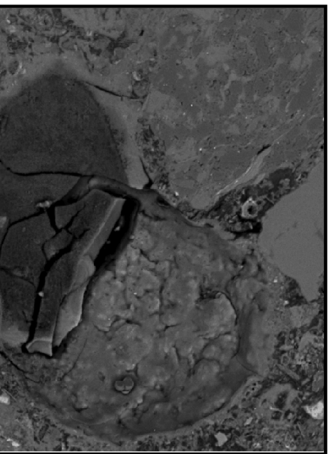

Fig. 7 BSE images and EDS analyses of polished section taken from mortar bar with 2.4 FM.

sion, which was the mortar bar with the FM of 2.4(Case D), showed the deteriorated cement paste and aggregate in the micrographs (Figs. 7(d) and (e)).

\section{Conclusions}

The experimental study on the effect of the fineness modulus of reactive metamorphic aggregate on ASR expansion showed that ASR expansion of mortar bars decrease in almost linear proportion to the fineness modulus. Mortar bars with each different fineness modulus exceeded the limit set by the mortar bar test (ASTM C 1260), except for the case of the mortar bar with the fineness modulus of 3.25. From the linear relationship between the FM and expansion of mortar bars, it was found that when the FM of reactive metamorphic aggregate was more than 3.0, expansion of mortar bars met the criterion of ASTM C 1260 test method. The results of SEM (SEI and BSEI) showed that the surface of the mortar bar with 3.25 FM was partially rough but the physical bond between particles and cement paste was generally intimate, and no traces of ASR were observed. In other mortar bars except for the mortar bar with $3.25 \mathrm{FM}$, it could be observed in the SEM SE images that there were the morphologies of reaction products on the surface. The BSE images of polished cross sections showed that there were reactive products in cement paste, within air void and within cracks through particles in the mortar bars exceeded the limit set by the standard. The EDS analysis of reactive products showed presence of silica, calcium and sodium, typical ASR product composition. The experimental study showed that, although only limited number of fineness modulus types were studied, ASR expansion could be controlled by the fineness modulus of reactive aggregate.

\section{Acknowledgments}

Ssang Sun Jun wishes to thank Prof. Paulo Monteiro at University of California for his invaluable help and many fruitful discussions. This project was supported by the Korea Research Foundation Grant funded by the Korean Government (MOEHRD) (KRF-2006-214-D00169). 


\section{References}

1. Garcia-lodeiro, I., Palomo, A., and Fernandez-Jimenez, A., "Alkali-Aggregate Reaction in Activated Fly Ash Systems," Cement and Concrete Research, Vol. 37, No. 2, 2007, pp. 175 183.

2. Ben Haha, M., Gallucci, E., Guidoum, A., and Scrivener, K. L., "Relation of Expansion due to Alkali Silica Reaction to the Degree of Reaction Measured by SEM Image Analysis," Cement and Concrete Research, Vol. 37, No. 8, 2007, pp. 1206 1214.

3. Tosun, K., Felekoglu, B., and Baradan, B., "The Effect of Cement Alkali Content on ASR Susceptibility of Mortars Incorporating Admixtures," Building and Environment, Vol. 42, No. 9, 2007, pp. 3444 3453.

4. Mo, X. and Fournier, B., "Investigation of Structural Properties Associated with Alkali-Silica Reaction by Means of Macro-and Micro-Structural Analysis," Materials Characterization, Vol. 58, No. 2, 2007, pp. 179 189.

5. Malvar, L. J., Cline, G D., Burke, D. F., Rollings, R., Sherman, T. W., and Greene, J. L., "Alkali-Silica Reaction Mitigation: State of the Art and Recommendations," ACI Materials Journal, Vol. 99, No. 5, 2002, pp. 480 489.

6. Chatterji, S., "Chemistry of Alkali-Silica Reaction and Testing of Aggregates," Cement and Concrete Composites, Vol. 27, Nos. 7 8, 2005, pp. 788 795.

7. Thomas, M., Fournier, B., Folliard, K., Ideker, J., and Shehata, M., "Test Methods for Evaluating Preventive Measures for Controlling Expansion due to Alkali-Silica Reaction in Concrete," Cement and Concrete Research, Vol. 36, No. 10, 2006, pp. 1842 1856.

8. Aquino, W., Lange, D. A., and Olek, J., "The Influence of Metakaolin and Silica Fume on the Chemistry of Alkali-Silica Reaction Products," Cement and Concrete Composites, Vol. 23, No. 6, 2001, pp. 485 493.

9. Lee, Y. S., Jaung, J. D., Noh, J. H., Cho, I. H., Yoon, J. H., and Lee, Y. S., "An Experimental Study on the Alkali-Silica Reaction of Crushed Stones," Proceedings of the Korea Concrete Institute, Vol.
6, No. 1, 1994, pp. 169 173.

10. Jun, S. S., "Alkali-Silica Reaction of the Domestic Crushed Stones on the Rock Types," Doctoral Dissertation, Pusan National University, 2006, pp. 7 15.

11. Lee, J. H. and Kim, S. W., "A Study on the AlkaliAggregate Reactivity in Crushed Stone by Chemical Method," Proceedings of the Korea Concrete Institute, Vol. 4, No. 2, 1992, pp. $25 \sim 30$.

12. Multon, S., Cyr, M., Sellier, A., Leklou, N., and Petit, L., "Coupled Effects of Aggregate Size and Alkali Content on ASR Expansion," Cement and Concrete Research, Vol. 38, No. 3, 2008, pp. 350 359.

13. Feng, N. Q., Hao, T. Y., and Feng, X. X., "Study of the Alkali Reactivity of Aggregates Used in Beijing," Magazine of Concrete Research, Vol. 54, No. 4, 2002, pp. 233 237.

14. Kosmatka, S. H. and Panarese, W. C., "Design and Control of Concrete mixtures," Portland Cement Association, Engineering Bulletin, $13^{\text {th }}$, 1990, pp. 30 46.

15. Diamond, S. and Thaulow, A., "A Study of Expansion due to Alkali-Silica Reaction as Conditioned by the Grain Size of the Reactive Aggregate," Cement and Concrete Research, Vol. 4, No. 4, 1974, pp. 591 607.

16. Lu, D., Mei, L., Xu, Z., Tang, M., and Fournier, B., "Alteration of Alkali Reactive Aggregates Autoclaved in Different Alkali Solutions and Application to Alkali-Aggregate Reaction in Concrete: (É) Alteration of alkali reactive aggregates in alkali solutions," Cement and Concrete Research, Vol. 36, No. 6, 2006, pp. 1176 1190.

17. Katayama, T., "How to Identify Carbonate Rock Reactions in Concrete," Materials Characterization, Vol. 53, Nos. 2 4, 2004, pp. 85 104.

18. Peterson, K., Gress, D., Dam, T. V., and Sutter, L., "Crystallized Alkali-Silica Gel in Concrete from the Late 1890s," Cement and Concrete Research, Vol. 36, No. 8, 2006, pp. $1523 \sim 1532$. 